\title{
Secondary Language Spoken
}

National Cancer Institute

\section{Source}

National Cancer Institute. Secondary Language Spoken. NCI Thesaurus. Code C132460.

Additional language(s) that is spoken by the subject but which is not considered the primary language. 